\title{
Biology society narrows Chinese rifts
}

\section{TAIPEI}

Warming scientific relations between Taiwan and mainland China were on view last week at a meeting in Taipei of the Society of Chinese Bioscientists in America (SCBA).

Historically a Taiwanese-dominated academic networking group, the society last week announced its first president-elect born and raised in mainland China: Xiao-Fan Wang, a cancer biologist at Duke University in Durham, North Carolina.

And a bill introduced in the Taiwanese legislature in January could mean that many more mainland Chinese scientists will be soon be living and working in Taiwan. The legislation would permit Taiwanese universities to recognize university degrees from mainland institutions such as Peking University and Tsinghua University. "It's ridiculous that we don't," says Ji-Wang Chern, dean of research and development at the National Taiwan University in Taipei.

Carmay Lim, a computational biophysicist at the Academia Sinica in Taipei, says she has not been able to offer $\mathrm{PhD}$ positions to mainland students whom she wanted to stay on in her lab. "Because of the politics between Taiwan and [mainland] China, scientists like myself lose good students to universities in other parts of the world," she says.

Few details of the bill are publicly available, but Chern says it is likely to be adopted. The proposal aligns with generally better relations between mainland China and Taiwan, especially since Ma Ying-jeou became president of Taiwan in May 2008.

The easing of tensions could be seen in the relaxed atmosphere of the SCBA meeting. Society scientists recall past episodes in which a senior education ministry official from Beijing stormed out after not being allowed to move her talk ahead of a Taiwanese scientist, and a 2001 meeting where Nobel laureate Yuan Tseh Lee suggested that China was hurting chances for diplomacy and scientific collaboration by building up missiles aimed at Taiwan. His counterpart from the Chinese Academy of Sciences defended China's actions as a valid protection against imperialism. "There has been nothing like that here," says Chung S. Yang, a cancer researcher at Rutgers University in Piscataway, New Jersey, and former SCBA president.

New society president Kuan-Teh Jeang, a virologist at the US National Institutes of Health in Bethesda, Maryland, says the SCBA will be changing dramatically in ways that could help to unite Chinese scientists. $\mathrm{He}$ hopes to turn it into an organization with more lobbying power, an enhanced role in advising government and academic institutions on interactions with Chinese institutions overseas and, possibly within a year, its own online open-access journal.

"We need to be ready to extend beyond niche special interests," he says. "We should participate in the mainstream."

David Cyranoski 